\title{
Trabalhar o mármore e o granito: entre cores e ritmos
}

\author{
Ariele Binoti Pacheco ${ }^{\mathrm{I}, 1}$, \\ Maria Elizabeth Barros de Barros ${ }^{\mathrm{I}, 2}$ e Claudia Osório da Silva ${ }^{\mathrm{II}, 3}$ \\ ${ }^{\mathrm{I}}$ Universidade Federal do Espírito Santo (Vitória, ES) \\ ${ }^{\text {II }}$ Universidade Federal Fluminense (Niteroi, RJ)
}

Este estudo busca dar visibilidade às criações que os trabalhadores do mármore e do granito de uma indústria no Espírito Santo engendram em seus fazeres diários, utilizando, com esse objetivo, as ferramentas teóricometodológicas da Clínica da Atividade. Visa, ainda, a propiciar que outras relações mais potentes possam ser (re)criadas por meio da ampliação de suas possibilidades de ação. Com vistas a esse objetivo, propõe a experimentação de um dispositivo denominado Oficina de Fotos, em que os trabalhadores produzem fotos de situações do ambiente e do processo de trabalho, as quais são confrontadas e analisadas pelos outros trabalhadores.

Palavras-chave: Análise do trabalho, Clínica da atividade, Poder de agir.

To work on marble and granite: between colors and rhythms

This study aims at giving visibility to creations by employees of an industry of marble and granite in the State of Espírito Santo in their daily routine, using for this the Clinic of Activity's theoretical-methodological tools. It also aims at enabling more powerful relationships to be (re)created through the expansion of its action possibilities. With this goal, this work proposes an apparatus called Photo Workshop in which workers produce photographs of situations of the environment and of their work process, and these images are confronted and analyzed by other workers.

Keywords: Work analysis, Clinic of activity, Power to act.

\section{Introdução}

A pesquisa trata de uma experimentação de análise dos processos de trabalho, usando a do Espírito Santo.

O Espírito Santo destaca-se no Brasil pela produção e exportação de rochas ornamentais. É o principal produtor do país, com 47\% do total brasileiro. Em 2008, as exportações capixabas giraram em torno de 630,3 milhões de dólares, com a comercialização de 1,12 tonelada de rochas, respondendo por $66 \%$ do faturamento e $56,5 \%$ do volume físico total brasileiro (Abirochas, 2009).

Essa é uma atividade que gera empregos e crescimento econômico, mas também é marcada pela precarização do trabalho, degradação do meio ambiente e elevado nível de acidentes de trabalho. Entre 1998 a 2008, dados oficiais demonstram que ocorreram 91 acidentes fatais no estado (Sindimármore, 2009).

1 Mestre em Psicologia Institucional pela Universidade Federal do Espírito Santo.

2 Professora Doutora do Departamento de Psicologia e do Programa de Pós-Graduação em Psicologia Institucional da Universidade Federal do Espírito Santo.

3 Professora Doutora do Departamento de Psicologia e Programa de Pós-Graduação em Psicologia - Estudos da Subjetividade da Universidade Federal Fluminense. 
Barulho, calor, umidade, poeira, peso, corte, esmagamento, arranhão, produto químico, monotonia, repetição... tudo isso faz parte do cotidiano desses trabalhadores. Mas como eles ${ }^{4}$ suportam essa situação? Parece que há algo ali que escapa a tudo isso, difícil de descrever, mas que é possível perceber nas conversas, nos olhares, no transitar entre as pedras, no fazer do dia a dia, no convívio.

Partimos à procura das inúmeras cores que emergem dos fazeres do mármore e do granito, buscando trilhar seus movimentos. Como surgem? $O$ que produzem esses trabalhadores? De que maneira tornam visível esse trabalho?

O som do encontro do trabalhador com a pedra esconde algo enigmático, que nem o ritmo taylorista conseguiu apagar: é a musicalidade da vida que pulsa nesses momentos. $\mathrm{O}$ trabalhador se confronta com variabilidades e exigências das situações de trabalho, e por isso sua atividade está sempre marcada por escolhas, valores e normas, produzindo desvios necessários para a realização das tarefas. A atividade de fato realizada a cada instante pelos trabalhadores "é sempre singular, uma tentativa do sujeito de produzir o seu meio, renormatizar, reinventar, mesmo que no mais ínfimo, as maneiras de viver (e trabalhar)" (Botechia, 2006, p. 145). Trabalhar coloca-se também como uma ação inventiva que se expande para além da pura execução de tarefas prescritas.

Mas o que se pode ouvir em uma serraria ${ }^{5}$ além do ziguezague irritante dos teares? ${ }^{6}$ No momento em que pedra, trabalhador e máquina parecem formar um só corpo, no barulho estridente dos teares, um ruído, a princípio totalmente despercebido, grita no ouvido aguçado dos trabalhadores, informando-lhes que a máquina precisa de reparos, que é preciso criar estratégias para que chapas de pedra não saiam empenadas.

O trabalho humano é criação, é invenção de novas formas de fazer. É própria do viver essa capacidade de criar, de instituir novas normas diante das infidelidades do meio. A vida não é, portanto, "para o ser vivo, uma dedução monótona, um movimento retilíneo; ela ignora a rigidez geométrica, ela é debate ou explicação... com um meio em que há fugas, vazios, esquivas e resistências inesperadas" (Canguilhem, 2007, p. 149).

Instigadas pelo trabalho com mármore e granito, algumas questões foram formuladas: como criar estratégias metodológicas que permitam compreender o caráter enigmático desta atividade? Como construir metodologias de análise do trabalho que possibilitem a transformação do vivido nesses locais de trabalho com vista à promoção da saúde?

Buscou-se, por meio de um dispositivo denominado Oficina de Fotos, construir caminhos que levassem à ampliação da potência de ação dos trabalhadores, no sentido de estabelecer melhores condições de vida no trabalho e, assim, criar uma relação mais prazerosa ${ }^{7}$ com o trabalho. A questão central da pesquisa foi a promoção da saúde, e não apenas a luta contra o sofrimento. ${ }^{8}$ Partiu-se, com os trabalhadores, à procura do inesperado nas situações de trabalho e da "presença da vida mesmo nas situações mais restritivas e difíceis" (Brito, 2004, p.

4 Embora o setor do mármore e do granito seja composto, predominantemente, por homens, as mulheres também estão presentes. Elas exercem, em geral, funções nas áreas de resinagem e polimento. $\mathrm{O}$ trabalho de campo desta pesquisa foi desenvolvido com homens que compõem a linha de ladrilhos de uma indústria de mármore e granito. No entanto, o contato com mulheres do setor colaborou muito para a construção da pesquisa.

5 Empresa que desdobra blocos de mármore e de granito em chapas.

6 Máquina que possibilita que um bloco seja desdobrado em chapas.

7 Tradicionalmente, o sentido de prazer está ligado à conquista de uma situação ideal, um estado de plenitude, que nunca é atingido, deixando o sujeito sempre numa situação faltosa e na busca de sua realização. Entretanto, na concepção de que falamos, o trabalho prazeroso é aquele em que o trabalhador participa de sua construção. "O sofrimento, a dor... estão ligados aos sentimentos de 'indignidade, de inutilidade e desqualificação' vividas pelos trabalhadores ao executarem uma tarefa aquém de sua capacidade inventiva" (Barros \& Barros, 2007, p. 66).

8 Neste caso, trata-se do sofrimento que nos paralisa, impedindo os movimentos de luta por melhores condições de trabalho/vida. Acreditamos que o sofrimento, quando não nos paralisa, pode, ao contrário, nos impulsionar na recriação de outras maneiras de viver, mais favoráveis à saúde. 
108). Falar de vida no trabalho é pensá-lo em seu caráter de imprevisibilidade, na capacidade de enfrentamento, de luta, de embate a perigos e riscos, de criação, de instituição de novas normas.

Numa indústria de rochas ornamentais, o risco de acidentes e de morte transita entre homens, máquinas e pedras, em um convívio de grandes tensionamentos. A luta pela saúde, pela vida, precisa ser diária.

A pesquisa procurou, a partir da análise das atividades de trabalho, seguir uma direção que pudesse contribuir para que os trabalhadores, como protagonistas desse processo, pudessem criar novos modos de fazer, inventar formas de enfrentar as situações no trabalho, por meio da ampliação de seu poder de agir, expandindo a vida. Toma-se, aqui, o conceito importante da proposta da Clínica da Atividade, na qual o poder de agir não está relacionado ao poder de executar atividades pelos trabalhadores, mas ao poder de afetar e de ser afetado.

Na perspectiva da Clínica da Atividade, que adotamos neste texto, vislumbra-se a transformação das situações de trabalho, considerando que os protagonistas das mudanças pretendidas são os próprios trabalhadores. A partir de uma retomada de Spinoza e Ricoeur, Clot forja esse conceito afirmando que o poder de agir diz respeito à atividade. O poder de agir nos dá a medida do raio de ação efetivo dos trabalhadores em situação de trabalho, diz do seu poder de recriação, o que o afasta da concepção de poder como coação. "O poder de agir é heterogêneo. Pode-se dizer que ele aumenta ou diminui em função da alternância funcional entre o sentido e a eficiência da ação em que se opera o dinamismo da atividade, ou seja, sua eficácia" (Clot, 2010a, p. 15). O autor nos adverte, entretanto, que não se trata de eficácia como chegada aos objetivos perseguidos. A noção de eficácia inclui a invenção de novos objetivos, e, logo, tem também caráter inventivo.

\section{Clínica da Atividade: uma ferramenta de trabalho}

A Clínica da Atividade, corrente francesa da psicologia que surgiu na França na década de 1990, chamou-nos especial atenção ao privilegiar a ação - clínica - em sua aposta teórico-metodológica. Yves Clot, seu autor mais eminente, propôs, desde então, uma "psicologia do desenvolvimento dos sujeitos no trabalho, incluindo ferramentas, coletivos e organizações" (Clot, 2010a, p. 12). Com esse objetivo, trabalha suas análises sobre a relação saúde/trabalho usando como principal ferramenta teórica o conceito de atividade de trabalho. É um conceito que tem uma história rica e complexa. Tomando as palavras de Yves Clot (2010b):

Vamos, no entanto, tentar "entrar" na clínica pela atividade. Fazê-lo é, com certeza, antes de tudo, convocar os usos da ergonomia, mas é sobretudo alinhar consigo um cortejo de autores da linhagem dos grandes russos dos anos vinte: Vigotski (1987, 2003, 2005; Clot, 1999a), Bakhtin (1984), Leontiev $(1976,1984)$, Luria (1985) e Rubinstein (2007), para citar apenas alguns (p. 13).

Trata-se de um trecho em que ele defende que a análise da subjetividade se faça tendo como entrada a atividade. Essa forma de aproximação caracteriza tal abordagem como uma clínica. No artigo, ele irá discutir o uso que faz desse conceito um psiquiatra, François Tosquelles, que diz da têmpera de autores, como Le Guillant ${ }^{9}$, Sivandon e Daumezon.

Atividade, na concepção da Clínica da Atividade, está relacionada com as "operações manuais e intelectuais realmente mobilizadas a cada instante pelo operador para atingir seus

9 Le Guillant é um autor que tem importante contribuição para as clínicas do trabalho. Alguns de seus escritos foram publicados no Brasil em Lima (2006), prefaciado por Yves Clot. 
objetivos, e não apenas pelas prescritas" (Clot, 2006, p. 24), porém não se restringe a elas. As atividades emergem opondo-se a tentativas frustradas de antecipação, de previsão e prescrição por meio de regras e normas para a execução das tarefas e correspondem a uma recriação que se dá entre os planos do prescrito e do real.

Os trabalhadores imersos em um mundo de acidentes possíveis (Canguilhem, 2007) são levados a "negociar" sempre com as regras prescritas, com os outros trabalhadores, com valores, não se submetendo inteiramente às regras, mas inovando, superando, produzindo regras. $O$ trabalho, nessa direção, é entendido como uma atividade construída e reconstruída no confronto dos trabalhadores com cada situação.

No desenvolvimento do conceito, chega-se à proposição de que atividade e subjetividade estão numa relação em que ambas são produção e produto de um mesmo processo (Osório da Silva, Barros \& Louzada, 2010).

No caso das indústrias de mármore e granito, caracterizadas por monotonia e repetição de tarefas, as prescrições parecem ditar o ritmo dos homens com a pedra. Entretanto, ao analisar a relação doença/acidentes/trabalho, é possível fazer emergir pistas de um real que transborda qualquer tentativa de antecipação, de prescrição.

Nas marcas que a pedra deixa no corpo, em forma de acidentes e doenças, vemos surgir o real da atividade, que escancara a variabilidade de um meio de trabalho o tempo todo infiel, jamais totalmente prescrito e previsto, fornecendo-nos pistas sobre as atividades realizadas, mas também sobre as possibilidades não realizadas (Canguilhem, 2001). Somos alertados para essa dupla faceta da atividade, que abrange também outras ações que não puderam se concretizar ou não foram alvo da escolha dos trabalhadores, permanecendo ocultas.

O trabalhador, cercado por (pré)ocupações, em situações em que deve escolher a melhor maneira de manusear uma chapa de pedra trincada a fim de evitar que ela se quebre, atento às metas e prazos de produção, incomodado com o calor produzido pelas luvas de proteção que fazem suar as mãos, tem ocupações que emergem entrecruzadas também com a atividade dos outros. Assim, a escolha de uma forma de fazer, de um caminho a ser tomado, significa deixar outros caminhos possíveis de lado: "A atividade afastada, ocultada ou inibida nem por isso está ausente. A inatividade imposta lança todo o seu peso sobre a atividade presente" (Clot, 2006, p. 116). Portanto, para analisar a atividade e compreender seu desenvolvimento, deve-se considerar essa parte oculta, impedida, que, em algum momento, concorreu com a atividade vencedora, com aquilo que, de fato, foi efetivado.

A atividade realizada compreende tudo aquilo que se faz nas situações de trabalho; a atividade real transborda as realizações dos operadores, abarcando as possibilidades não realizadas, as intenções dos operadores que não chegaram a ser efetivadas, os caminhos que foram recusados, mas que nem por isso têm sua importância reduzida.

Já o ofício em que essa atividade se exerce é pensado num plano processual onde se entrecruzam quatro dimensões. É uma dimensão transpessoal, pois é atravessada e produzida por uma história coletiva. Essa dimensão se constitui como uma memória do trabalho, da qual os trabalhadores podem dispor como instrumento para agir diante dos inesperados do real. Mas o ofício é também e simultaneamente pessoal, interpessoal e impessoal. Pessoal em cada atividade singular. Interpessoal porque é endereçado, isto é, não existe sem um destinatário, é sempre dirigido simultaneamente para seu objeto e para as outras atividades ligadas a esse objeto, sejam as de outro trabalhador, sejam ainda outras atividades do sujeito. E, ainda, impessoal porque diz respeito à prescrição, à organização oficial do trabalho. A prescrição é indispensável e sempre alimentada pelo trabalho transpessoal. 
Nessa perspectiva, uma clínica da atividade não perde de vista que a transformação do trabalho passa pela tarefa prescrita. Ela tem como horizonte o desenvolvimento do poder de agir sobre a organização do trabalho (Roger, 2007). ${ }^{10}$

A dimensão transpessoal ou genérica é igualmente contida na tarefa (impessoal) e na atividade (pessoal e interpessoal). É a discordância entre essas quatro dimensões que a conserva (dimensão transpessoal), mesmo que de maneira provisória, já que sempre será retocada, reconfigurada na ação. "A atividade pessoal e interpessoal no trabalho engendra esta memória transpessoal revitalizando-a, recriando-a” (Roger, 2007, p. 22). Essa memória dá suporte às atividades e as (pré)organizam fornecendo modos de agir, de vestir, de falar etc. generalizáveis em um determinado ofício e formando o gênero de atividade profissional.

Sem os recursos para ação disponibilizados pelo gênero da atividade profissional dimensão transpessoal do ofício -, os trabalhadores sozinhos, diante de si mesmos, têm seu poder de agir enfraquecido. O gênero é o que permite, por exemplo, que um polidor (operador de máquina polideira, que confere brilho às pedras), em seu primeiro dia de trabalho em uma nova empresa, saiba como começar e terminar uma tarefa, isto é, colocar a chapa de pedra na bancada, ver se as chapas estão sendo bem polidas pela máquina, utilizando-se de expressões e realizando ações que se compõem com as de seu ajudante, com o qual nunca trabalhou antes, mas tudo isso deve se efetivar de maneira eficaz para a realização do polimento. Pode-se dizer que toda ação estará necessariamente apoiada em dimensões genéricas, isto é, em uma zona comum de saberes-fazeres formada por trabalhadores que fazem parte de um mesmo horizonte profissional e social.

Mas o gênero não pode ser considerado como algo dado, acabado; pelo contrário, ele se caracteriza por sua processualidade e abertura a transformações, atualizando-se a cada situação e englobando a história de fazeres e saberes compartilhados pelos trabalhadores. Ao (pré)organizar as operações, o gênero convoca uma reconstrução de regras, de novas formas de fazer, exigindo um estilo que se apropria de elementos transpessoais, mas também imprime pessoalidade à ação, um modo próprio de fazer.

É o estilo que participa da renovação do gênero, reavaliando-o constantemente e conferindo-lhe movimento. Assim, um maior conhecimento do gênero pelo trabalhador possibilita que se liberte dele e o recrie de forma estilística. "O estilo retira ou liberta o profissional do gênero, não negando este último, não contra ele, mas graças a ele, usando seus recursos, suas variantes, em outros termos, por meio de seu desenvolvimento, impelindo-o a renovar-se" (Clot, 2006, p. 41).

O trabalho em uma polideira automática exige que o trabalhador passe grande parte de sua jornada atento à máquina, acompanhando seu movimento. Há momentos, como analisou Clot (2006), a partir de estudos com condutores de trens, em que ocorre uma suspensão do espírito, e o trabalhador se distrai. Por isso, é comum vermos polidores lendo jornais, cujo objetivo é não se distrair além da medida, permanecendo presente à situação.

A criação estilística funciona como uma ferramenta profissional e pode ser incorporada a um patrimônio do ofício, enriquecendo o gênero. Por meio de uma análise da atividade, a relação criativa do trabalhador com seu objeto oferece oportunidades para que a relação dos outros trabalhadores com esse mesmo objeto seja renovada, desembocando no desenvolvimento dos objetos, dos trabalhadores e da atividade coletiva.

Os estilos são, portanto, uma reformulação dos gêneros, isto é, a transformação dos gêneros pelos trabalhadores em recursos para agir nas situações reais de trabalho, promovendo seu desenvolvimento. Portanto, são as atividades dos sujeitos que mantêm vivos os gêneros. $\mathrm{O}$ sujeito se produz ao colocar o mundo a seu favor, ao torná-lo um "mundo para si", integrando-se a ele, reformulando-o (Clot, 2006). 
Como, então, possibilitar que um gênero profissional que se encontra fragilizado possa ser reativado, revitalizado, a fim de se promover saúde nos ambientes de trabalho? De quais instrumentos se pode fazer uso com vistas a alimentar o poder de agir dos trabalhadores no seu meio de trabalho?

Encontram-se, então, na Clínica da Atividade alguns métodos de análise da atividade de trabalho que visam a possibilitar (trans)formações no que é vivido nos ambientes laborais. Há interlocução forte com o trabalho produzido por Oddone (1986), que propõe um deslocamento de protagonistas quando se deseja observar e interpretar as situações de trabalho. Segundo o autor, esta tarefa deve ser conduzida pelos trabalhadores, que são levados a observar e interpretar suas próprias ações com o objetivo de se libertar das maneiras como habitualmente pensam e dizem suas atividades, para refletir de forma diferente da usual (Clot, 2010).

Entendendo que a ação se transforma ao passar pelo "crivo do pensamento" (Vygotski, 1994, citado por Clot, 2000), pode-se, então, dizer que esses métodos de ação (sobre o trabalho) permitem restaurar o poder de agir dos trabalhadores em situação real. Ao se tornar observador de seu próprio trabalho, outras tantas possibilidades de ação podem emergir, modificando-se o desenrolar das atividades do sujeito.

Seguindo a direção de uma análise do trabalho que valoriza a atividade, Clot e Faïta (2000) propõem a autoconfrontação cruzada. ${ }^{11}$ Nesse método, os trabalhadores dialogam consigo mesmos e com outros (pesquisador, colega de trabalho) sobre imagens em vídeo de seu trabalho. Seu objetivo (Clot, 2006, 2010a) é criar um espaço-tempo diferente das situações habituais, em que não se apliquem as regras do cotidiano de trabalho que dizem respeito ao que é correto e incorreto, às relações de hierarquias e aos efeitos que elas produzem. Não se busca, com esse método, uma simulação das situações de trabalho, mas, sim, confrontá-las, possibilitando uma reconcepção, isto é, seu desenvolvimento. Nessa direção, a autoconfrontação cruzada não se restringe nem pretende ser apenas um meio de colocar em palavras as ações realizadas pelos trabalhadores, mas se configura como uma nova atividade.

Na primeira etapa, o trabalhador comenta sua atividade de trabalho para o analista do trabalho. Já na segunda, além do analista do trabalho, o trabalhador confronta sua atividade com a de um colega. Isso é importante, porque tanto o analista quanto os colegas de trabalho têm dúvidas e questionamentos distintos sobre as imagens e, por isso, produzem um acesso diferente ao real. A atividade de comentário dos dados registrados com as filmagens é, em cada caso, redirecionada a determinado destinatário, o que modifica a análise. Ao explicar suas atividades a alguém que não é do mesmo ofício, o trabalhador faz um esforço para que ele as entenda, o que propicia uma reflexão sobre seu trabalho. Produz-se, nessa relação, um estranhamento daquilo que entre pares poderia ser tido como óbvio (Osório da Silva, 2002). A cumplicidade existente em um mesmo ofício pode deixar muitas respostas implícitas, que a ingenuidade profissional do não especialista acaba por tornar visíveis.

Os métodos de autoconfrontação não visam a uma simples descrição da experiência, mas produzem uma nova experiência. Longe de ser apenas uma representação da ação passada, uma troca entre os atores envolvidos, a análise da atividade inscreve-se numa perspectiva desenvolvimentista, que considera que a experiência tem uma história e que sua análise transforma essa história (Clot, 2000). As experimentações de autoconfrontação cruzada põem em movimento a atividade, constituindo-se como um meio de formação pautado na ação, em que se confrontam diferentes maneiras de fazer para atender aos mesmos objetivos e se criam outras tantas que possibilitem superar as dificuldades encontradas nas situações de trabalho, na

11 Alguns pesquisadores brasileiros (Amador, 2009; Louzada, 2008; Osório da Silva, 2002; Santorum, 2006; Vasconcelos, 2008) vêm desenvolvendo dissertações e teses nessa direção metodológica. Desde 2007, o Núcleo de Estudos e Pesquisas em Subjetividade e Políticas do Departamento de Psicologia da Universidade Federal do Espírito Santo tem experimentado dispositivos de análise da atividade de trabalho de professores da Rede Pública de Ensino da Serra-ES por meio de fotografias (Oficina de Fotos) e filmagens (autoconfrontação cruzada). 
perspectiva de sua transformação. Esse processo de form(ação) envolve criação e experimentação constante de novas maneiras de fazer no próprio cotidiano de trabalho.

Esta pesquisa foi, então, construída apostando que não basta apenas compreender para transformar. É preciso também transformar para compreender.

\section{Oficina de Fotos}

Inspiradas nas experiências de autoconfrontação cruzada propostas pela Clínica da Atividade e apostando que a análise das situações de trabalho a partir de imagens poderia disparar questionamentos e reflexões que permitissem que outras formas de trabalhar e viver fossem produzidas, foram construídas algumas vias metodológicas. $\mathrm{Na}$ Oficina de Fotos, os trabalhadores produzem fotografias de situações do seu trabalho a serem analisadas pelo próprio grupo, ocorrendo confrontações, na medida em que pesquisadores/analistas do trabalho e fotógrafos comentam e analisam as atividades de trabalho.

É importante destacar que a Oficina de Fotos é um dispositivo construído no diálogo que se dá em cada intervenção, a partir das experiências com os trabalhadores. Não existe, portanto, um roteiro de ações que deve ser seguido, uma técnica a reproduzir, o que estaria em discordância com a própria Clínica da Atividade e com o que se acredita ser um instrumento potente de transformações dos meios de trabalho. Existem, sim, direções, orientações e princípios que norteiam as ações dos analistas do trabalho, com o objetivo de auxiliar os trabalhadores na análise da atividade, possibilitando a ampliação da potência de ação e a transformação dos cotidianos de trabalho que produzem adoecimento.

No primeiro encontro, foi apresentada a proposta para uma equipe de nove trabalhadores, que se constituíram como o grupo associado da pesquisa. Dentre esses, o grupo escolheu quatro para participar como fotógrafos, atuando em duplas. No segundo, cada dupla de fotógrafos elaborou um roteiro das situações de trabalho a serem fotografadas e produziu as fotos das situações a serem retidas para análise. Ainda no segundo encontro, as imagens foram coletivamente analisadas. No terceiro, duas duplas de fotógrafos reuniram-se com a equipe de pesquisa para a seleção das fotos que seriam postas em debate no grupo associado. As imagens foram exibidas (usando um notebook) para a outra dupla. Todos comentaram e confrontaram o material. No quarto encontro, o grupo associado analisou as fotos produzidas. A seguir, foi proposto que os trabalhadores elaborassem um painel com as fotos, atribuindo-lhes títulos; o painel seria, então, exibido ao restante dos trabalhadores da empresa, ampliando a discussão e produzindo ressonâncias do trabalho realizado. Os trabalhadores sugeriram que fossem também criadas legendas para cada foto.

Em mais dois encontros, foi confeccionado o painel. Cada legenda criada convocava as hierarquias e todos os trabalhadores da empresa a pensar questões referentes ao trabalho.

Os fotógrafos decidiram organizar as fotos em dois conjuntos, para serem afixadas no painel, e criaram os seguintes títulos: Alegria e satisfação gera produção, para as fotos de situações que os fortalecem, potencializam-nos no trabalho, e Prevenir é melhor que remediar, para as fotos de situações que os enfraquecem, fazem-nos sofrer no trabalho.

Preocupava-nos a possibilidade de a oficina ter caráter apenas denunciatório das más condições de trabalho ou de culpabilização de trabalhadores. Como afirma Osório da Silva (2002), "a denúncia de más condições, embora muitas vezes necessária, apresenta limitações: leva a reivindicações de transformações de caráter geral, nem sempre atendidas, sem interferir na capacidade de ação e nos recursos subjetivos dos trabalhadores para esta ação" (p. 101). 
A direção da empresa demonstrou interesse no processo disparado e não se furtou ao debate. Quatro semanas após a montagem do painel, foi realizado um encontro de restituição.

\section{Fotografias em foco: analisando a atividade}

De um total de 43 fotos, o grupo de fotógrafos selecionou 12 para serem apresentadas ao grupo associado.

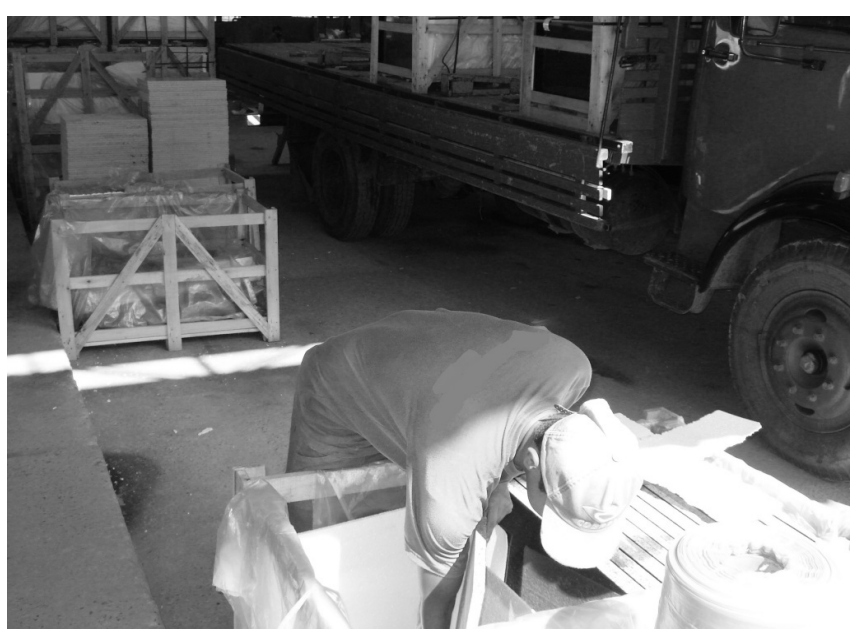

Fotografia 1: Vamos mudar o jeito de trabalhar?

Essa posição é prejudicial à saúde. Vamos criar sistemas de trabalho melhores para nosso bem-estar ! ${ }^{12}$

A Fotografia 1 registra o processo de carregamento de ladrilhos. Devido às paredes altas do caixote, os trabalhadores precisam inclinar o corpo, provocando uma sobrecarga na coluna vertebral. $\mathrm{O}$ abastecimento das máquinas e o encaixotamento de ladrilhos exigem carregamento de peso. Os ladrilhos medem $60 \times 60 \mathrm{~cm}$ e pesam cerca de 45 a 55 quilos. Em um curso de segurança no trabalho, os trabalhadores relataram que o engenheiro de segurança os instruíra a se agachar ao colocar o ladrilho dentro do caixote de madeira. No entanto, devido à altura das paredes do caixote e ao peso da pedra, eles precisam inclinar-se.

De modo geral, os treinamentos de segurança no trabalho não levam em conta as situações reais a que o trabalhador está sujeito. A lógica das ações de formação costuma ser a de fracionamento das situações de trabalho, não se questionando as situações reais. Seu verdadeiro objetivo é tornar suportáveis as situações de trabalho, promovendo a adaptação dos trabalhadores (Duraffourg, 2000, citado por Schwartz \& Durrive, 2007).

Durante esta pesquisa, foi possível conhecer histórias de trabalhadores que estão o tempo todo lutando para suportar o insuportável. Paulo (nome fictício), afastado por problemas de coluna, tem 35 anos e trabalha há nove na empresa. Atualmente, está na função de cortador. Em suas falas, em tom depressivo, expressou a preocupação em voltar logo ao trabalho e as dificuldades de um trabalho penoso: "Há dois anos, tive problemas na coluna e fiquei nove meses afastado. Achei que ia melhorar, mas voltou tudo. Não gosto de ficar em casa, porque preciso trabalhar pra cuidar dos meus filhos e da minha esposa".

$\mathrm{Na}$ semana seguinte, o mesmo trabalhador estava na máquina do corte. Ele dizia que seus músculos doíam e que não estava "aguentando parar em pé". Seu olhar de resignação parecia aceitar sua condição. Com a saúde degradada e um sofrimento paralisante, ficava 
visível a redução do poder de agir desse trabalhador. Mesmo em situações extremas, quando a dor era grande, ele continuava na máquina.

A saúde, na concepção adotada, está relacionada com a capacidade de lidar com as infidelidades e variações do meio. Ser sadio significa não se submeter inteiramente a determinada situação, mas ser normativo, isto é, ser capaz de instituir novas normas de vida diante das exigências do meio (Canguilhem, 2007). Os trabalhadores se sentem bem, com saúde, na medida em que são capazes de criar saídas para as diversas situações nos ambientes de trabalho, quando podem ser responsáveis pelos seus atos, sentindo-se ativos, podendo intervir na organização do trabalho. Nesse sentido, a descoberta de um novo objetivo possível, ignorado até então, o reconhecimento de outra coisa que seria feita através ou além do que vem a se realizar e a identificação de possibilidades desconhecidas no real podem promover o desenvolvimento do poder de agir. A remobilização do sujeito diante do conjunto de novas possibilidades de ação que agora o habitam leva a uma revitalização da atividade propulsora do desenvolvimento do poder de agir e de sua vitalidade.

No decorrer da Oficina de Fotos, à medida que os trabalhadores eram incentivados, eles se sentiam mais confiantes em trazer para discussão situações de trabalho penosas. Ao mesmo tempo, alternativas eram criadas com vistas a tornar as condições de trabalho mais favoráveis à saúde.

No início da realização da oficina, as falas dos trabalhadores vinham acompanhadas de uma perspectiva que eternizava as situações vividas, consideradas imutáveis, que tomava lugar da vontade de ação: "Não adianta falar nada, ninguém ouve". Entretanto, a possibilidade de intervir de fato em seu processo de trabalho produzia saúde; o conformismo dava lugar às ideias; o olhar de resignação, a um olhar contagiante de alegria. Pôr em análise os processos e condições de trabalho possibilitou a criação e a experimentação de outros modos de fazer. "A gente podia tirar uma das laterais do caixote e escorá-lo em algum lugar firme pra ele não abrir. Depois de carregado, a gente coloca a lateral." "Temos de pensar alguma coisa pra carregar o palete. Podíamos fazer uma bancada pra que fique mais alto e uma bancada também para os caixotes".

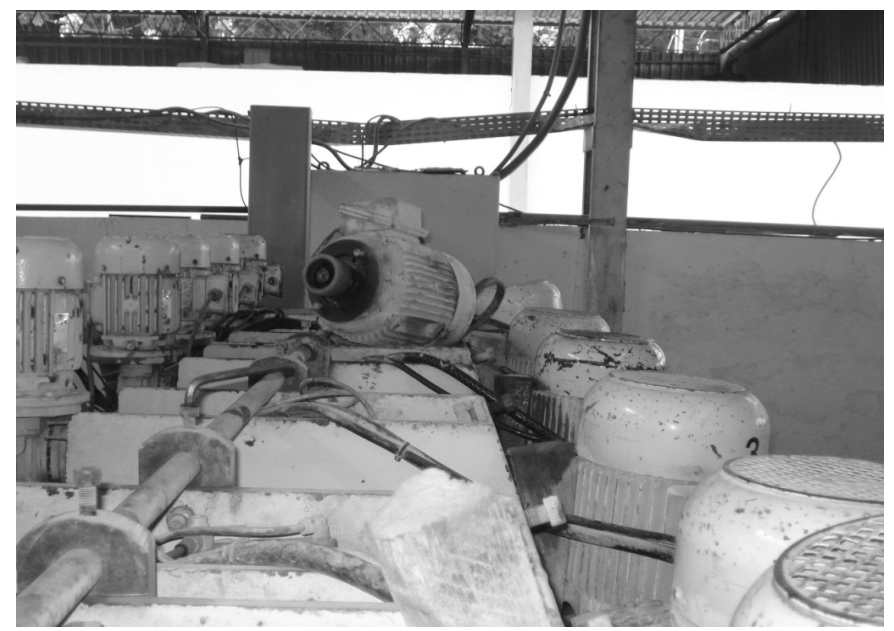

Fotografia 2 - Gambiarras permanentes

Não temos condições de trabalhar com essas gambiarras. Assim, não conseguimos produzir o necessário!

A Fotografia 2 mostra a multidisco (máquina de corte) com uma série de cunhas (pedaços de madeira) segurando os cabeçotes (onde são fixados os discos de corte). Os trabalhadores contam que estão sempre tendo de "dar um jeitinho nas máquinas" quando precisam de algum reparo. Poder fazer pequenos reparos na máquina para que ela volte a funcionar rapidamente é visto com grande satisfação pelos trabalhadores. No entanto, quando isso ocorre, dificilmente a máquina é consertada pelo setor de manutenção: "É bom poder dar um jeitinho para não parar a máquina e a produção por muito tempo, mas deveria ser por 
pouco tempo. Logo o mecânico deveria ir lá consertar, e não a gente ficar o tempo todo dando jeitinho". "É uma gambiarra que você faz pra poder continuar trabalhando com a máquina, mas, depois que você fez, a gambiarra fica o resto da vida lá".

Um polidor diz que sua máquina sempre está com problemas no sistema automático e que, hoje, ele precisa controlar 12 satélites manualmente, acarretando mais trabalho e produzindo menos: "O que era pra produzir 200 metros produz 150, fora a raiva que a gente passa!". As "gambiarras" chamam especial atenção, pois estão presentes em grande quantidade nas máquinas. O que essas gambiarras indicam? Que valor está sendo dado a esse trabalho? $\mathrm{O}$ que se percebe, na maioria das empresas, é o aumento do número de gambiarras, e os trabalhadores tendo de produzir a mesma quantidade com a mesma qualidade de uma máquina sem defeitos. Dessa maneira, gasta-se menos com manutenção, e o resultado é praticamente o mesmo em termos de produção, porém a saúde dos trabalhadores fica cada vez mais degradada.

Diante desse contexto, o gênero profissional dessa atividade torna-se cada vez mais fragilizado, pois os recursos de que comumente lançam mão para lidar com as situações cotidianas de trabalho, com tantas situações em que é preciso "dar um jeitinho na máquina" para que ela volte a funcionar com a mesma qualidade e produtividade, acabam reduzidos. Tendo de conciliar o inconciliável, sem os recursos necessários para agir, os trabalhadores têm seu poder de agir diminuído, o que acarreta adoecimento (Clot, 2006).

Trabalhar sob essas condições é ter sua atividade impedida. Como nos alerta Clot (2006), a inibição de sua ação pode ser tão desgastante quanto a própria atividade do sujeito:

Aquilo que não se pode fazer e o que se quereria fazer conta pelo menos tanto quanto aquilo que se faz. Seus esforços não são apenas aqueles que ele faz para [manejar a máquina], mas igualmente aqueles que eles devem aceitar para reprimir sua própria atividade e a dos outros (p. 122).

Um polidor tenta traduzir em palavras o desprazer produzido pela impossibilidade de realizar sua tarefa: "Quando a máquina está com problemas, eu perco até a vontade de ir na garrafa de café".

Impõe-se aos trabalhadores uma inatividade mais custosa que a própria tarefa prescrita, gerando uma tensão que, ao não se dissipar em ação, torna-se fatigante. $\mathrm{O}$ aumento de trabalho e a preocupação com o julgamento que é feito pelos pares e supervisores devido aos defeitos nas máquinas também são destacados por este polidor:

Quando o material vem com marca de serrada [com uma pequena valeta no meio da chapa], eu preciso tirar isso, mas não vejo problema nisso. Só que, como a máquina está no manual, preciso me esforçar bem mais que o normal para tirar a marca, o que normalmente já daria trabalho. $\mathrm{O}$ material chega lá embaixo, e tem de voltar para fazer de novo. Aí o pessoal lá de baixo não entende, acha que a gente não sabe fazer.

Como aponta Clot (2006), as ocupações dos trabalhadores irão emergir entrecruzadas por essas pré(ocupações), que dizem respeito a como seu trabalho é avaliado pelos pares e supervisores, como sua forma de fazer irá influenciar o trabalho dos outros que estão no fim da linha de produção. Suas escolhas e maneiras para realizar a atividade estarão permeadas por essas pré(ocupações).

Nesse sentido, um polidor trabalhando em sua máquina nunca estará sozinho. Podemos dizer que "ele está isolado daqueles com quem trabalha, mas cuja presença invisível não cessa de se manifestar" (Clot, 2006, p. 111). Sua atividade real estará marcada pelas ressonâncias das/nas atividades dos outros, isto é, dos serradores, que, na atividade de serragem dos blocos para o desdobramento em chapas, ficaram com marcas de serrada; dos selecionadores, que classificam o material também de acordo com a qualidade do polimento; dos vendedores, que vendem os ladrilhos, produto final da linha de produção. Sua atividade é, portanto, dirigida 
simultaneamente ao seu objeto da ação (chapa de pedra e polideira) e às outras atividades ligadas a esse objeto, sejam as de outro trabalhador (supervisor, cortador, selecionador de ladrilhos, vendedor), sejam ainda outras atividades do sujeito. Sua atividade é, então, dirigida a diversos interlocutores e é também destinatária da atividade dos outros.

O polidor é o ponto de interseção das múltiplas atividades dos outros e, como um intercambiador das atividades dos outros, irá transformá-las em recursos para sua própria ação. É por meio desses diálogos invisíveis com outros trabalhadores, ao qual sua atividade é endereçada, e de suas respostas presumidas, que o polidor seleciona o modo como polir a chapa de pedra com marca de serrada, isto é, os modos de agir fornecidos pelo gênero profissional que está a sua disposição.

O trabalho é sempre uma prova, entendendo-se pelo termo uma situação que não oferece todas as respostas às questóes que ela mesma levanta: uma situação que convoca então o sujeito, remetendo-o aos outros, a si mesmo, ao objeto de seu trabalho e a seus instrumentos de ação e, por fim, aos esperados genéricos de sua atividade (Clot, 2006, p. 111).

A atividade de retirar a marca de "serrada" da chapa de pedra é a que o trabalhador não pôde fazer, a que ele buscava, mas não conseguiu. Isso se expressa em sua fala como um fracasso, como uma atividade impedida devido a problemas técnicos da máquina. Quando se restringe a análise às atividades que foram realizadas - no caso, polir a chapa sem retirar totalmente a marca de "serrada" -, muitas vezes, considera-se que é um trabalhador negligente ou não é um bom profissional. No entanto, quando ele, como protagonista do processo de análise, é convocado a analisar essas questões, as possibilidades não realizadas e as variabilidades dos sistemas técnicos ganham visibilidade, permitindo-se compreender as situações de trabalho e transformá-las.

Ao colocar essas questões em debate com todos os trabalhadores, possibilitou-se o fortalecimento do coletivo de trabalho. As angústias, o julgamento feito pelos colegas de trabalho e os desprazeres são trazidos à cena e discutidos. Situações semelhantes vividas por outros trabalhadores emergem em suas falas: "Eu chego de manhã, tem material jogado perto da máquina, que o pessoal da noite deixou lá. Aí eu vou lá e tiro. No outro dia, continua a mesmo coisa, aí eu não tiro mais, não adianta falar com eles... aí acham que sou eu que deveria tirar e não tiro".

Esse debate alimenta o poder de agir dos trabalhadores, que passam a pensar juntos em maneiras de transformar essas situações: "Vamos fazer uma reunião com os donos da empresa, falar sobre o problema das máquinas, vamos ver se isso resolve". "Vamos chamar o pessoal da manutenção para conversar. Será que o problema não está na falta de pessoal? Tem muita máquina aqui, ou será que é a empresa que não libera a compra de peças pras máquinas?".

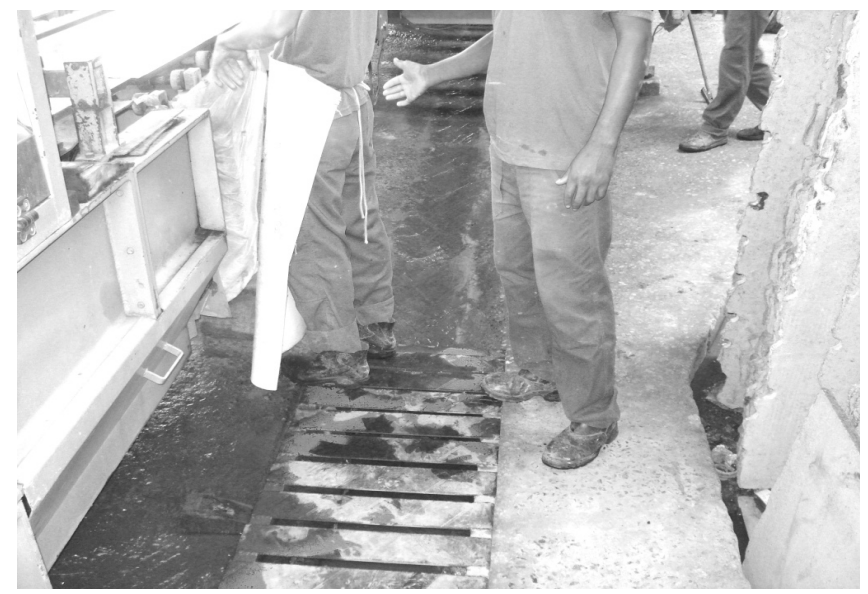

Fotografia 3 - Limites nas brincadeiras

O certo é tratar o companheiro da maneira como eu gostaria de ser tratado. 
A Fotografia 3 retrata as brincadeiras que acontecem no trabalho. Alguns trabalhadores não gostam das brincadeiras e apelidos, o que gera conflitos: "Uma vez, alguém brincou e a pessoa disse que iria entregar pro encarregado. Aí, pouco tempo depois, a pessoa foi chamada. Foi morrendo de medo, mas chegou lá e era outra coisa".

Vemos, nesse momento, a potencialidade do dispositivo para disparar diversas perspectivas de análise. A autoconfrontação cruzada com as duas duplas de fotógrafos produziu um deslocamento do ponto de vista de uma das duplas, que pode ser expresso nos comentários acerca da foto:

A gente fica trabalhando nove horas por dia sem poder brincar. Isso descontrai. Vou fazer uma coisa lá na frente, aí passo pelo pessoal do bisote e falo: "Para de morcegar, vai trabalhar!". Ou, então, aperto na bunda de alguém. Eu brinco com ele, ele ri, eu também dou gargalhada, passa um bem-estar muito grande, muito grande mesmo, dá mais ânimo pro cara trabalhar. Eu não me vejo trabalhando sem isso. Mas tem gente que não gosta, tem de saber com quem pode brincar. Tem gente que dá um tapão forte na bunda que dói.

Para a outra dupla de fotógrafos, não se trata de proibir o hábito de brincar, mas de saber como brincar com cada colega. Esses trabalhadores veem as brincadeiras como de fundamental importância para que o trabalho se torne menos cansativo, como algo que agrada e produz prazer. Essa interferência do par/colega de trabalho produz um movimento no diálogo em curso e nos leva a pensar a importância do par especialista na situação de análise em confrontação. Na coanálise que se desenrola, o diálogo entre os trabalhadores possibilita dar visibilidade ao gênero, que é trazido à cena pela confrontação do trabalhador com sua própria atividade e com a de outro trabalhador. A autoconfrontação permite reviver o gênero, oferecendo aos trabalhadores a possibilidade de aperfeiçoá-lo. Novas variantes podem surgir, validadas de forma coletiva pelos trabalhadores. O gênero se mantém assim vivo, isto é, servindo como instrumento de ação, quando se transforma alimentado pelas contribuições estilísticas (Clot, 2006).

\section{Encontro de restituição}

Seis semanas após a confecção do painel, que foi afixado no refeitório da empresa, trabalhadores e pesquisadores reuniram-se para analisar e avaliar a realização da Oficina de Fotos com todos os trabalhadores. Alguns relataram que vários colegas haviam se interessado pelo painel. Passando por ele, paravam e olhavam as informações, outros perguntaram do que se tratava.

Os trabalhadores indicavam que ainda há muito a ser feito, que, embora tivessem acontecido algumas melhorias, era necessário que outras ações fossem realizadas. Um trabalhador disse: "Esse é o caminho que nós temos para melhorar a situação". Outro trabalhador, avaliando a oficina, afirmou: "É bom se as nossas ideias forem acatadas".

Um participante sugeriu a realização de uma reunião com os proprietários da empresa e encarregados, mas, ao mesmo tempo, perguntou se todos se prontificavam a falar essas questões na reunião. Muitos ficaram calados, indicando dificuldade em trazer as questões para serem discutidas. Outro trabalhador sugeriu que fossem tiradas novas fotos mostrando o que havia mudado e o que não havia mudado, indagando por que algumas situações não mudam. Depois de vários debates sobre qual das estratégias deveria ser feita primeiro - reunião ou nova oficina - , os trabalhadores decidiram pela oficina. 


\section{Nova Oficina de Fotos}

Dois trabalhadores se prontificaram a produzir novas fotos. A partir das discussões do encontro anterior, fizeram as fotos do que havia melhorado e do que não havia mudado. Dois dias após, os fotógrafos e dois outros trabalhadores que vieram à empresa apenas para o encontro - ambos trabalham em escala de revezamento - reuniram-se e, após definir o que gostariam de mostrar, decidiram montar outro painel com as fotos antigas e as novas, fazendo um antes e depois das situações fotografadas.

Acima das fotos, foram colocadas as palavras antes e depois e criadas legendas e um título para o painel: "Pequenos problemas sempre haverá. O que não podemos deixar é que eles se tornem grandes problemas".

A nova Oficina de Fotos ocorreu quase dois meses depois do término da primeira. Nesse período, aconteceram mudanças que os trabalhadores creditam ao primeiro trabalho com as fotos. Quando trazem o antes e depois, pretendem mostrar como podem intervir/ transformar muitas situações quando se organizam.
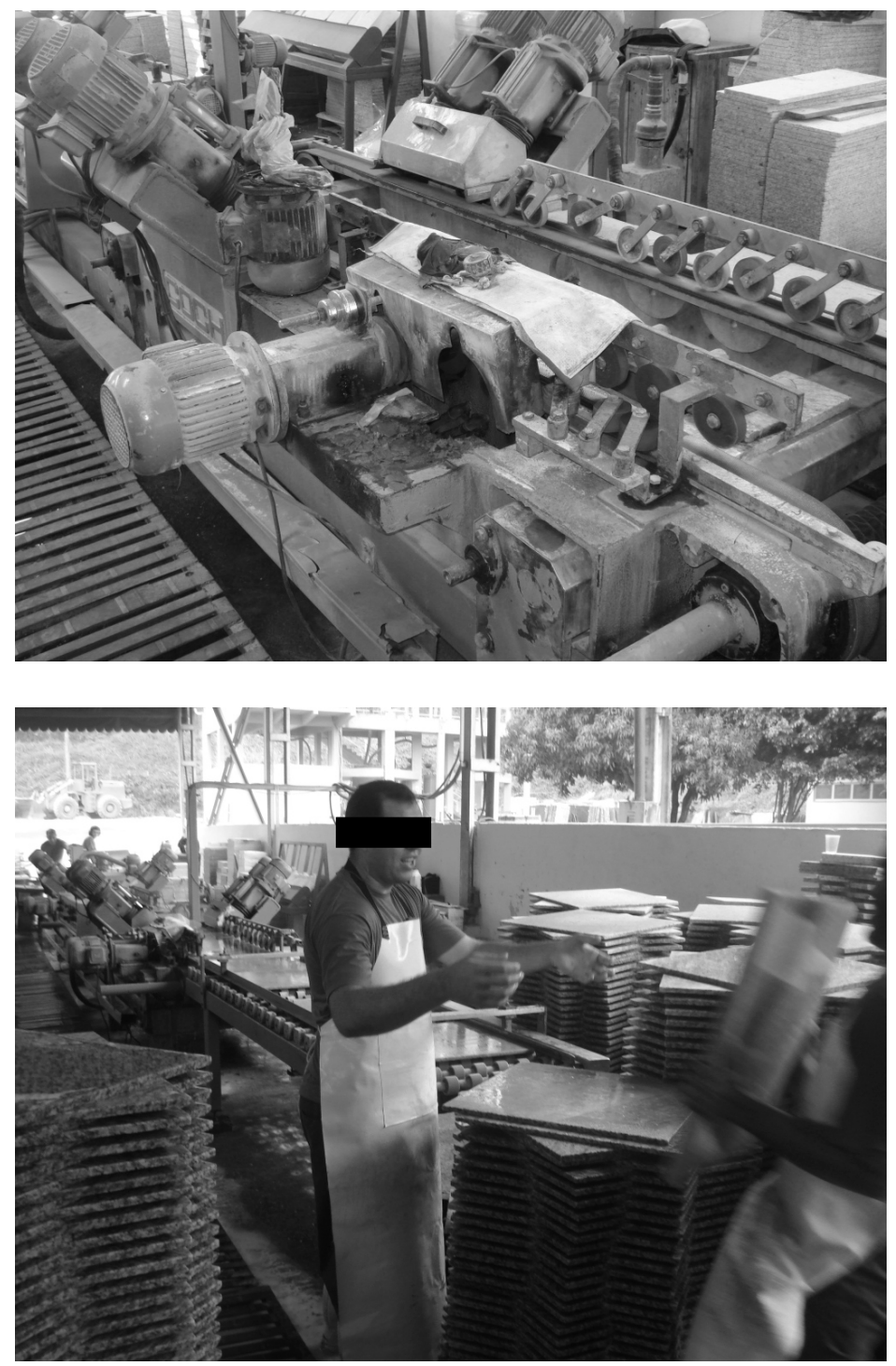

Fotografia 5 - DEPOIS

Antes faltava uma fresa no bisote 2. Com o problema solucionado, não precisamos mais empurrar o material na esteira. Com isso, o funcionário que ficava ajudando a empurrar as pedras exerce outra função. 


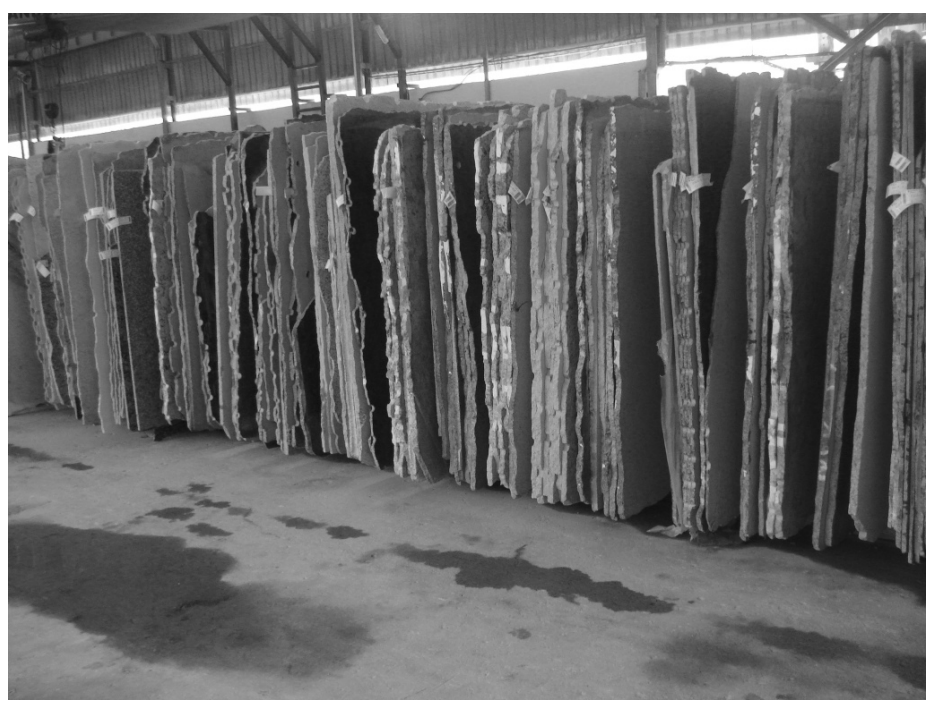

Fotografia 6 - ANTES

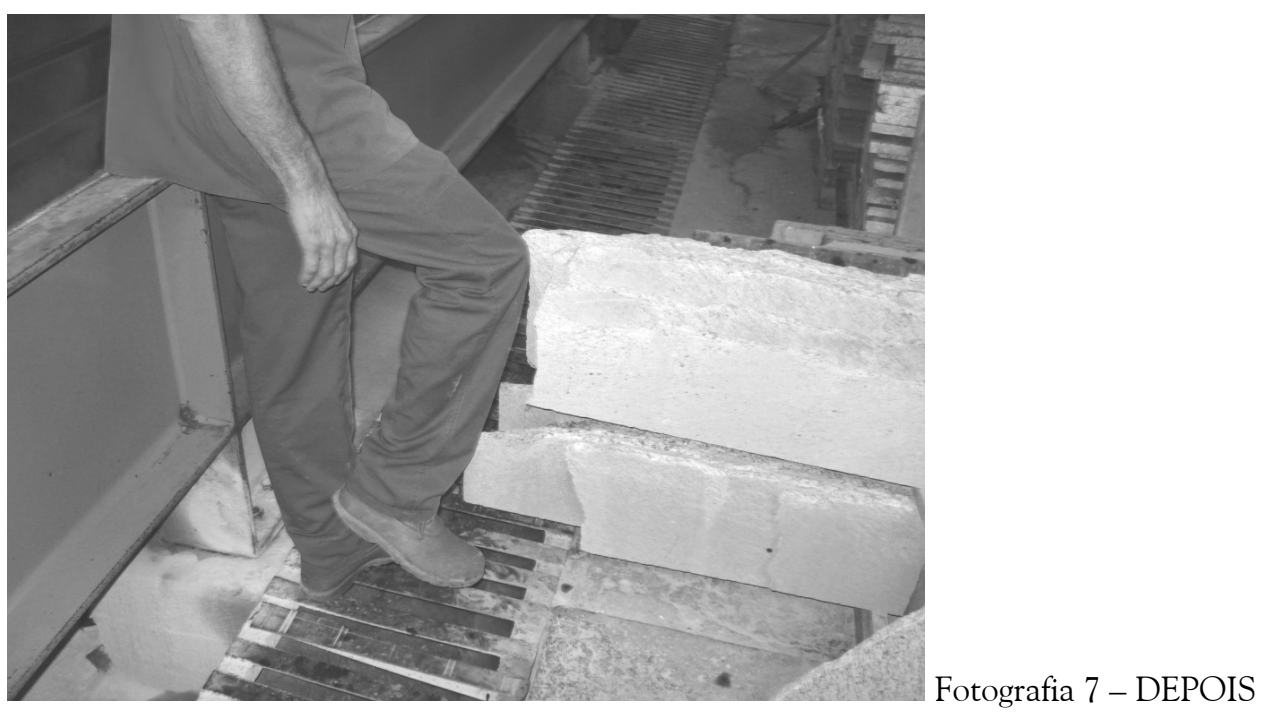

Como melhorou o espaço com a organização! Antes, as pedras estavam fora do lugar, ocupando espaço desnecessário, podendo fazer que um funcionário se machuque. Agora, o ambiente se tornou até mais bonito, limpo e mais seguro para o funcionário trabalhar.

\section{Considerações Finais}

No início da pesquisa, foi possível perceber um gênero profissional enfraquecido, a saúde estava desafiada até seus limites e o trabalho trazendo adoecimento. Mas, ainda assim, o gênero permitiu que os trabalhadores suportassem e sobrevivessem às condições adversas. Certamente, os saberes de prudência que passavam uns para os outros possibilitaram trabalhar em meio tão nocivo e, também, o aprendizado no trabalho naquele meio laboral. A repetida quebra de algumas máquinas e as permanentes más condições de outras, fazendo que os trabalhadores estivessem o tempo todo precisando "dar um jeitinho" para que elas voltassem a funcionar, chamaram a atenção: até que ponto e com quais efeitos para seus protagonistas resistirá um gênero cuja organização de trabalho é frágil? De que recursos genéricos poderiam lançar mão em situações imprevisíveis? Como dar visibilidade às criações que os trabalhadores do mármore e do granito engendram em seus fazeres diários? Imersos em um plano de atividades impedidas, assistia-se a uma atrofia do poder de agir, o que produzia um sofrimento paralisante. 
Apesar dessa situação, a empresa era bastante interessada nas questões relacionadas a saúde/trabalho e estava disposta a colaborar com a pesquisa. Havia grande disponibilidade de parar as máquinas quando proposto, como parte da análise em curso, o que significava manter uma equipe inteira sem trabalhar por até três horas consecutivas. A organização de turnos de trabalho foi alterada para a realização da pesquisa. Os trabalhadores diretamente envolvidos na pesquisa, os nove componentes do grupo associado, trabalham em escala de revezamento. Para viabilizar a Oficina de Fotos, foram mantidos, durante o período da pesquisa, apenas no turno do dia.

Um dos efeitos do trabalho realizado foi possibilitar aos trabalhadores do mármore e do granito experimentarem a importância do coletivo em seu trabalho. Uma necessidade inesgotável de trazer mais situações que precisavam ser repensadas, modificadas, tomava a todos. Uma pequena pedra havia sido lançada pelas montanhas que marcam a paisagem da região do mármore e do granito. A aposta é que ela se transforme em uma avalanche: de ideias, de ações! Nas palavras um trabalhador: "Esse é o caminho para que as mudanças ocorram, agora é continuar batalhando!".

A ampliação do poder de agir desses trabalhadores ficou evidenciada no enriquecimento do número de ações possíveis por meio de uma renovação do gênero profissional e também nas modificações conquistadas na relação desses profissionais com a dimensão impessoal do trabalho, isto é, nas condições de trabalho, prescrições, definições de tarefas. Máquinas foram consertadas; os cavaletes de chapas de pedras foram organizados; foram pactuadas outras maneiras de fazer para se evitar que pedaços de chapas fiquem espalhados pela área de produção; a forma de carregamento de ladrilhos está sendo repensada; outros aspectos, como remuneração e benefícios, puderam ser discutidos.

Entretanto, algumas questões se colocam: esse modo de intervenção, dependendo de como efetivamente se realiza, não poderia adquirir um caráter apaziguador? Apaziguador da luta, das (trans)formações efetivas na relação capital-trabalho...

O dispositivo(Oficina de Fotos) é paradoxal, porque, dependendo do uso que se faz dele, pode servir para inibir futuras e mais radicais ações, amortizando a luta capital-trabalho. Mudanças aconteceram imediatamente após a oficina, como, por exemplo, o conserto de algumas máquinas. Os trabalhadores queriam que as máquinas fossem consertadas, mas, paradoxalmente, essas ações poderiam intensificar o ritmo de trabalho e produzir carga maior de trabalho. Como a pesquisa pode contribuir nesse sentido?

Certamente esse dispositivo não resolve os problemas referentes à relação capital/trabalho, mas, como apontam os autores indicados ao longo do texto, aumentar o poder de agir e afirmar autonomia são alguns caminhos que podem levar a modificações mais radicais nos processos de trabalho que coloquem em questão a lógica do capital. $\mathrm{O}$ intuito não foi docilizar os trabalhadores, mas dar visibilidade a esse poder de agir e ampliá-lo, fortalecer coletivos de trabalho, para que eles possam se desdobrar em outras ações imprevisíveis. Os trabalhadores trouxeram muitas outras situações que precisam ser modificadas. Falavam que a mudança apenas havia começado, mas ainda faltava muito a ser feito, e começavam a listar o que precisava mudar. Cada vez mais, viam a importância de pensar de forma coletiva e sobre a força que possuíam juntos. Nas frases dos painéis, convocavam os trabalhadores a se unirem. Tendo seu poder de agir ampliado, os trabalhadores podem vislumbrar outros caminhos. $\mathrm{O}$ movimento de confrontação sobre a atividade de trabalho não tem limites; pode produzir ressonâncias num processo contínuo de análise que não se encerra, e que a última palavra não pode ser dita. Concordamos com Clot (2006) quando afirma que a sabedoria merece respeito quando acompanhada de audácia. 


\section{Referências}

Amador, F. S. (2009). Entre prisões da imagem, imagens da prisão: um dispositivo tecno-poético para uma Clínica do Trabalho. Tese de Doutorado, Programa de Pós-Graduação em Informática na Educação, Universidade Federal do Rio Grande do Sul, Porto Alegre.

Associação Brasileira da Indústria de Rochas Ornamentais - Abirochas. (2009). Balanço das exportações brasileiras de rochas ornamentais em 2008. Recuperado em 20 de março, 2009, de www.abirochas.com.br.

Barros, M. E. B. de \& Barros, R. B de. (2007). Da dor ao prazer no trabalho. In S. E. Santos \& M. E. B. de Barros (Orgs.), Trabalhador da saúde: muito prazer! Protagonismo dos trabalhadores na gestão do trabalho em saúde. Ijuí: Unijuí.

Botechia, F. R. (2006). O desafio de compreender-desenvolver um regime de produção de saberes sobre o trabalho e suas relações: a Comunidade Ampliada de Pesquisa. Dissertação de mestrado, Pós-Graduação em Psicologia Social, Universidade do Estado do Rio de Janeiro, Rio de Janeiro.

Brito, J. (2004). Saúde do trabalhador: reflexões a partir da abordagem ergológica. In M. Figueiredo et al. (Orgs.), Labirintos do trabalho: interrogações e olhares sobre o trabalho vivo. Rio de Janeiro: DP\&A.

Canguilhem, G. (2001). Meio e normas do homem no trabalho. Proposições, 12 (2-3), 35-36.

Canguilhem, G. (2007). O normal e o patológico (6 ${ }^{\mathrm{a}}$ ed.). Rio de Janeiro: Forense Universitária.

Clot, Y. (2000). La formation par l'analyse du travail: pour une troisième voi. B. Maggi (Org.), Manières de penser, manières d'agir em éducation et em formation (pp. 133-156). Paris: PUF.

Clot, Y. (2006). A função psicológica do trabalho. Petrópolis: Vozes.

Clot, Y. (2010a). Trabalho e poder de agir. Belo Horizonte: Fabrefactum.

Clot, Y. (2010b). Pourquoi l'activité dans la clinique du travail. In Y. Clot \& D. Lhuilier (Orgs.), Agir en clinique du travail (Collection Clinique du Travail). Toulouse: Erès.

Clot, Y. \& Faïta, D. (2000). Genres et styles en analyse du travail. Concepts et méthodes. Travailler, 4, 7-42.

Lima, M. E. A. (Org.). (2006). Escritos de Louis Le Guillant. Petrópolis: Vozes.

Louzada, A. P. (2008). Um trabalho docente: a invenção como imanente à vida. Projeto de Doutorado apresentado ao Programa de Pós-Graduação em Educação para fins de qualificação, Universidade Federal do Espírito Santo, Vitória.

Oddone, I. et al. (1986). Ambiente de trabalho: a luta dos trabalhadores pela saúde. São Paulo: Hucitec.

Osório da Silva, C. (2002). Vida de hospital: a produção de uma metodologia para o desenvolvimento da saúde do profissional de saúde. Tese de Doutorado, Escola Nacional de Saúde Pública, Fundação Oswaldo Cruz, Rio de Janeiro.

Osório da Silva, C., Barros, M. E. B. de \& Barros, Louzada, A. P. F. (2010). Clínica da Atividade: dos conceitos às apropriações no Brasil. In P. F. Bendassoli \& L. A. Soboll (Orgs.), Clínicas do Trabalho: novas perspectivas para compreensão do trabalho na atualidade. São Paulo: Atlas.

Roger, J.-L. (2007). Refaire son métier: essai de clinique de l' activité. Ramonville Saint-Agne: Èrés.

Santorum, K. M. T. (2006). Pelas fendas do trabalho vivo: textos, contextos e atos na atividade de vigilância em saúde do trabalhador. Tese de Doutorado, Fundação Oswaldo Cruz, Rio de Janeiro.

Schwartz, Y. \& Durrive, L. (2007). Trabalho e ergologia: conversas sobre a atividade humana. Niterói: Eduff.

Sindicato dos Trabalhadores na Indústria de Mármore, Granito e Calcário do Espírito Santo - Sindimármore. (2009). Estatísticas do setor do mármore e granito/ES. Recuperado em 4 de março, 2010, de www.sindimarmore.com.br/

Vasconcelos, D. (2008). Experimentações em Clínica da Atividade: cartografias na escola. Dissertação de Mestrado, Programa de Pós-Graduação em Psicologia Institucional da Universidade Federal de Espírito Santo, Vitória.

Vasconcelos, R. \& Lacomblez, M. (2005). Redescubramo-nos na sua experiência: o desafio que nos lança Ivar Oddone. Laboreal, 1 (1), 38-51.

\section{Endereço para correspondência}

ariele.binoti@hotmail.com, betebarros@uol.com.br, claudia.osorio.uff@gmail.com 